\title{
Exploration of Retinopathy Disease using Machine Learning Methodology
}

\author{
Khasanah, Sumardiyono, Phong Thanh Nguyen, E. Laxmi Lydia, K. Shankar
}

\begin{abstract}
The whole world is affected with the problem of Diabetic Retinopathy. Whenever a patient has diabetes, it starts affects human body sensitive parts. So the situation becomes very dangerous for the person. Here in this research work it is tried to detect Hemorrhages and micro aneurysms in multiple fundus images collected from various research institutes worldwide and available datasets. In initial it is required to separate RGB colors from the image. The green color is used for further processing. Further the grey color image is extracted for getting the texture of the input image. The feature extraction algorithms are used to classification. So that it is possible to predict the current situation of the retinal image. Once the situation is classified the segmentation algorithms are used using adaptive thresholding segmentation.

Keywords: Diabetic Retinopathy, Segmentation Algorithm,
\end{abstract} Grey Scale Image, RGB Images.

\section{INTRODUCTION}

Diabetic retinopathy (DR) is a vascular disease of the retina which affects patients with diabetes mellitus. The entire world is influenced with the issue of Diabetic Retinopathy. At whatever point a patient has diabetes, it begins influences human body touchy parts. So the circumstance turns out to be exceptionally perilous for the individual.

Here in this examination work it is attempted to distinguish Hemorrhages and miniaturized scale aneurysms in numerous fundus pictures gathered from different research foundations worldwide and accessible datasets. In beginning it is required to isolate RGB hues from the picture. The green shading is utilized for further handling. Further the dim shading picture is extricated for getting the surface of the information picture. The component extraction calculations are utilized to grouping. With the goal that it is conceivable to anticipate the present circumstance of the retinal picture. When the circumstance is arranged the division calculations are utilized utilizing versatile thresholding division.
Revised Manuscript Received on July 22, 2019

Khasanah, STMIK Indonesia Jakarta, Jakarta Pusat, Indonesia. Email:khasanah.pase@gmail.com

Sumardiyono, Department of Public Health, Faculty of Medicine, Universitas Sebelas Maret, Surakarta, Indonesia.

Phong Thanh Nguyen, Department of Project Management, Ho Chi Minh City Open University, Vietnam.

E. Laxmi Lydia, Vignan's Institute of Information Technology (A), Department of Computer Science and Engineering, Visakhapatnam, Andhra Pradesh, India.

K. Shankar, Department of Computer Applications, Alagappa University, India.

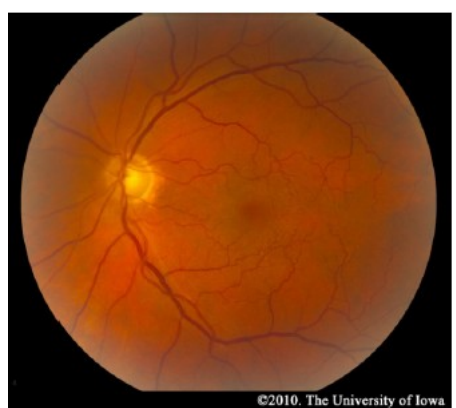

Fig.1. Normal Fundus

Glucose control likewise has the additional advantage of diminishing danger for opposite end-organ difficulties of diabetes, so it is significant that diabetic patients are instructed on the theme.

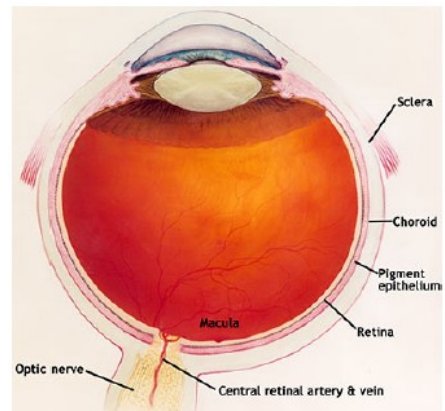

Fig.2. Diagram of Normal Eye Anatomy

The retina is one of the most sensitive part of eye and also it is a group of layers. It is one of the most metabolically dynamic organs in the body, and thus, it is amazingly touchy to ischemia and supplement irregular characteristics (Bengin 2004).

\section{Classification}

DR is classified into two main classes depends on the effects on retina. The first class tells weather retina is effected or not and the second class tells that the eye condition is stable.

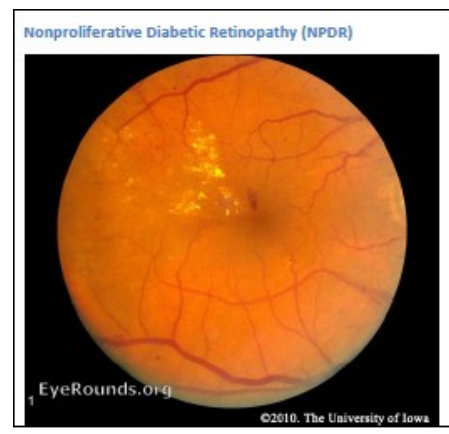

Fig. 3. NPDR

Published By:

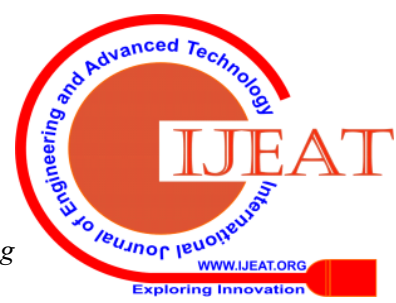




\section{Exploration of Retinopathy Disease using Machine Learning Methodology}

\section{Images and pictures}

The human eye takes vision as in input and the life of human completely relays the visuals he is seeing by eyes. Using those visuals the objects are identified and classified. As well an overall rough feeling for a sence is obtained.

\section{Image Processing on Datasets}

In order to apply image processing on datasets a number of steps are acquired. The steps are explained in brief below

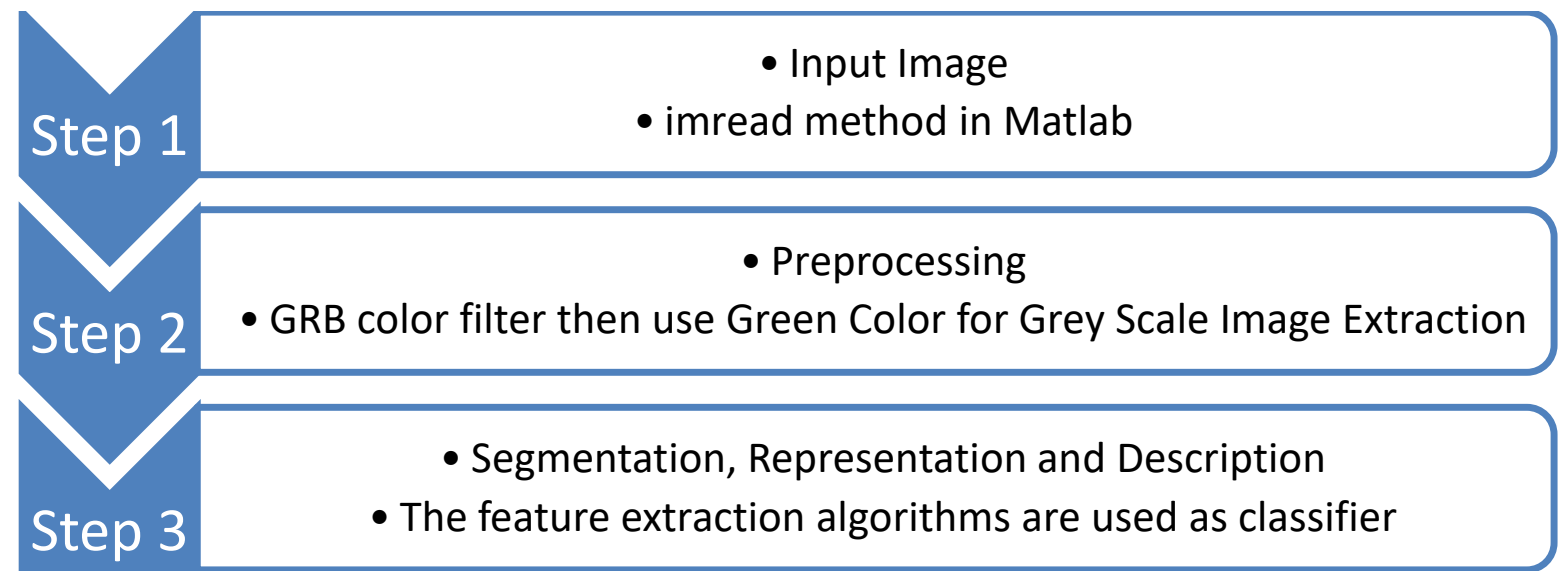

Fig. 4. Image Processing

II. PROBLEM FORMULATION AND OBJECTIVE

In order to segmentation, the image is analyzed and it type of pattern is recognized. This is the most important part and it is also the most difficult in order to obtain the results. The image segmentation is the process to segment an image into regions. These regions can be used for classification and feature extraction.

\section{K-means Clustering}

K-Means calculation is a solo bunching calculation that orders the info information focuses into various classes dependent on their inalienable good ways from each other.[3]

- Diabetic Retinopathy (DR) is one of the main sources of visual impairment in the industrialized world.

- Early recognition is the key in giving compelling treatment.

- However, the present number of prepared eye care pros is lacking to screen the expanding number of diabetic patients.

- In late years, mechanized and semi-computerized frameworks to recognize DR with shading fundus pictures have been created with empowering, yet not completely palatable outcomes.
III. IMPLEMENTATION

\section{Test Environment}

\begin{tabular}{|l|l|}
\hline Processor & $\begin{array}{l}\text { Intel }{ }^{\circledR} \text { Core }^{\mathrm{TM}} \text { i5 Processor } \\
2.40 \mathrm{GHz}\end{array}$ \\
\hline RAM & $8 \mathrm{~GB}$ \\
\hline OS & $64 \mathrm{bit}$ \\
\hline Software & MATLAB R $2015 \mathrm{~b}$ \\
\hline
\end{tabular}

- Resize of Image

- Morphological operations and Conversion

- Neighborhood and block operations

- Filter of Image

- Image transformation

- Analyze and enhancing of image.

- Image registration

- Region of interest operations 


\section{DESIGN Methodology}

The proposed work given in the flow diagram below:

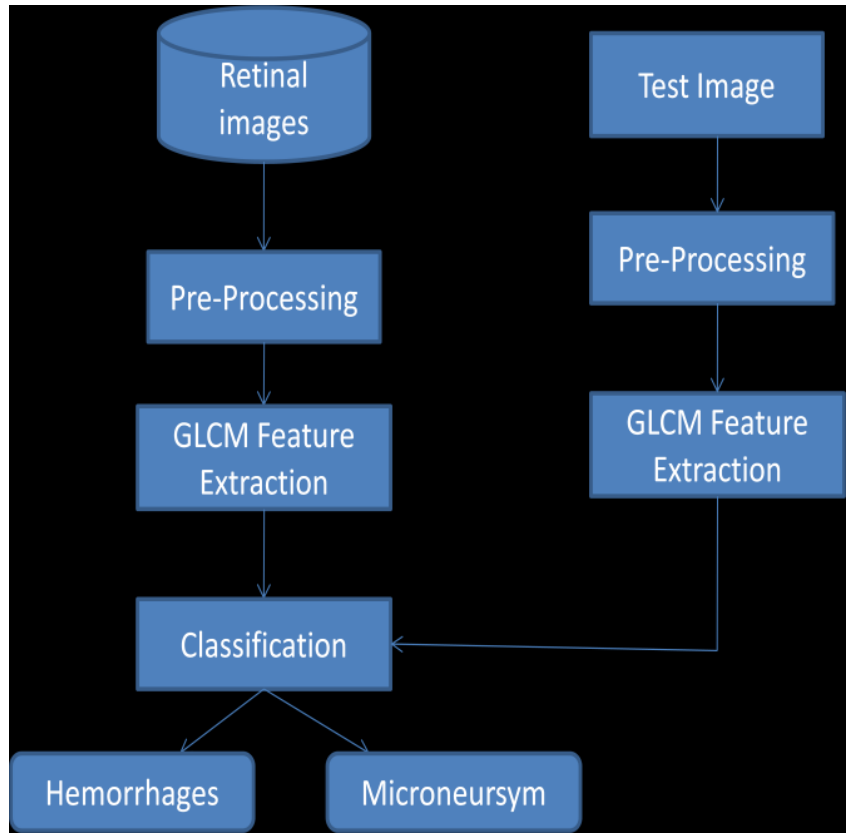

Fig. 5. Working model of proposed system

Phase 1

\section{Datasets Pre-processing}

Images are enhanced by sharpening and removing unwanted outliers.

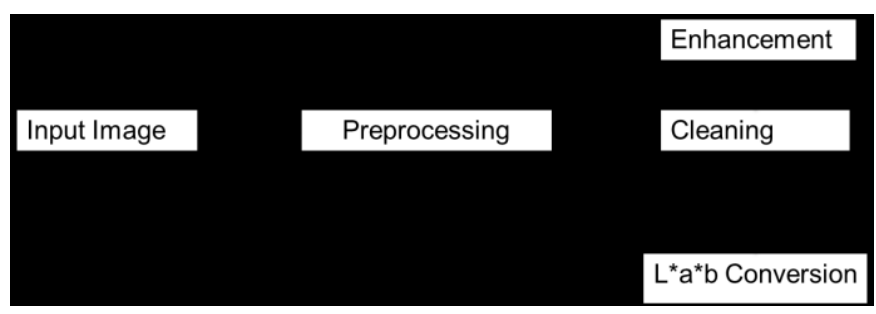

Fig.6. Image processing

\section{Phase 2}

\section{Datasets Image Segmentation}

Image will be segmented to fetch out the image edges and then detected all required parameters

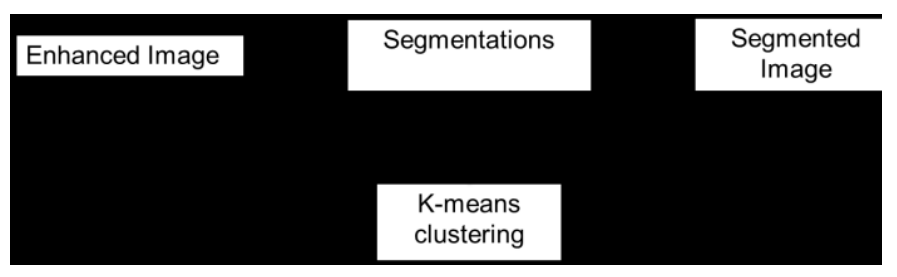

Fig.7. Segmentation

\section{Phase 3}

\section{Recognition and Classification}

Ones the image is segmented it can be tested to recognize it first and then classify it into original or fraud image using SVM algorithm.

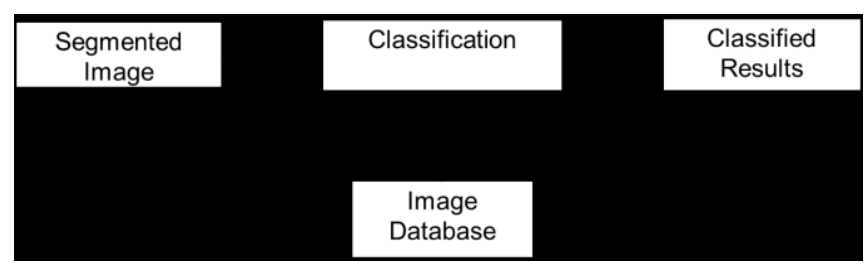

Fig.8. SVM Algorithm

In the proposed work, here to develop a system to detect fraud coins and notes currency for Indian Notes. Clustering will be done using k-means algorithm. Recognition and classification will be done using SVM algorithm.

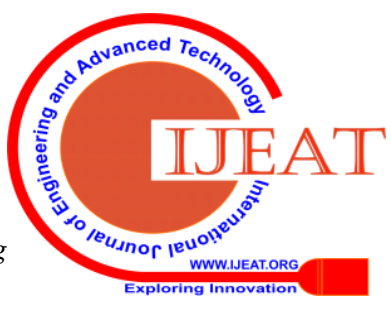




\section{Exploration of Retinopathy Disease using Machine Learning Methodology}

\section{DESIGN Methodology}

GUI

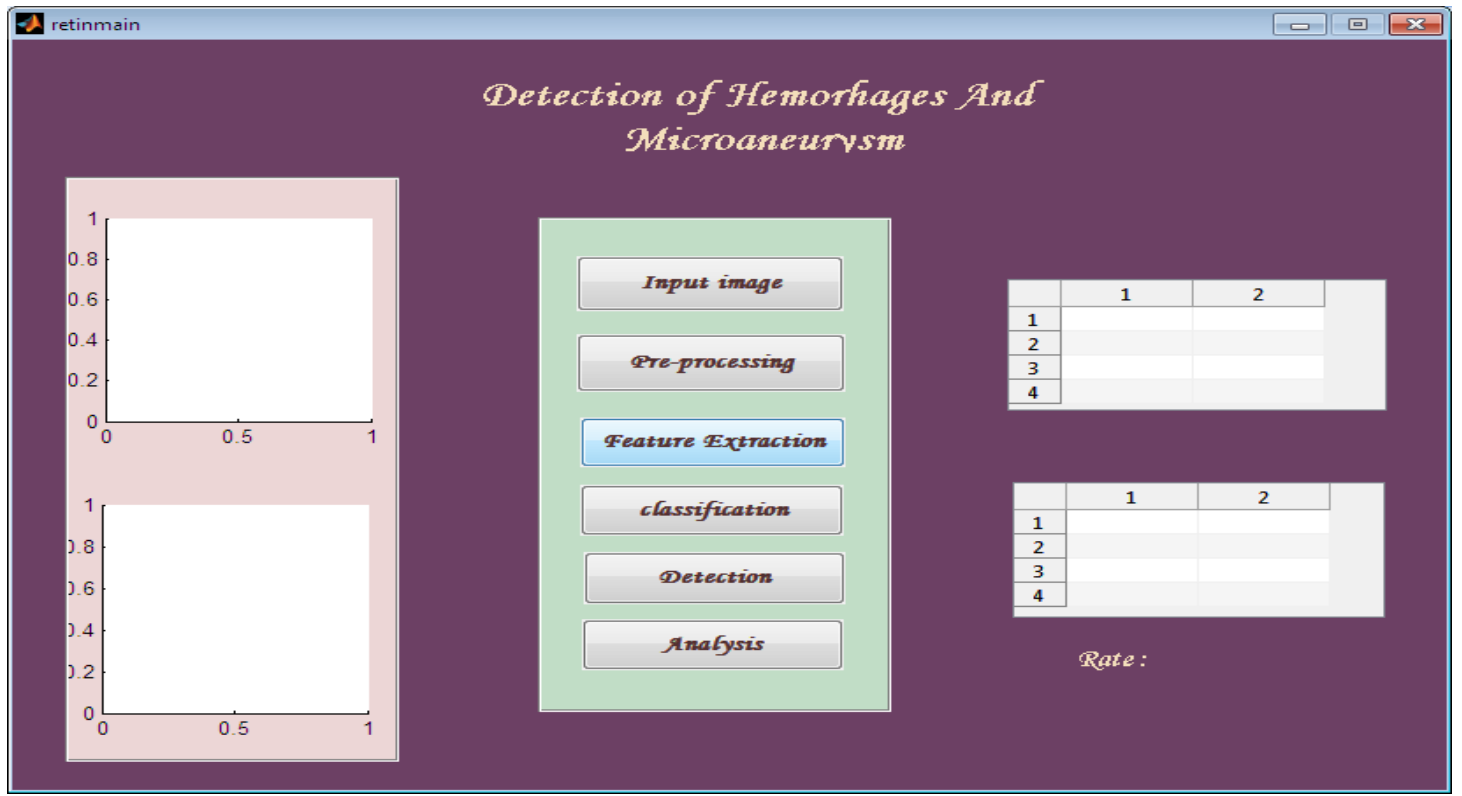

Fig.9. Front UI of the system.

In this form they have provided user with different GUI components for accessing the proposed system.In above form they have provided six buttons with four plots.
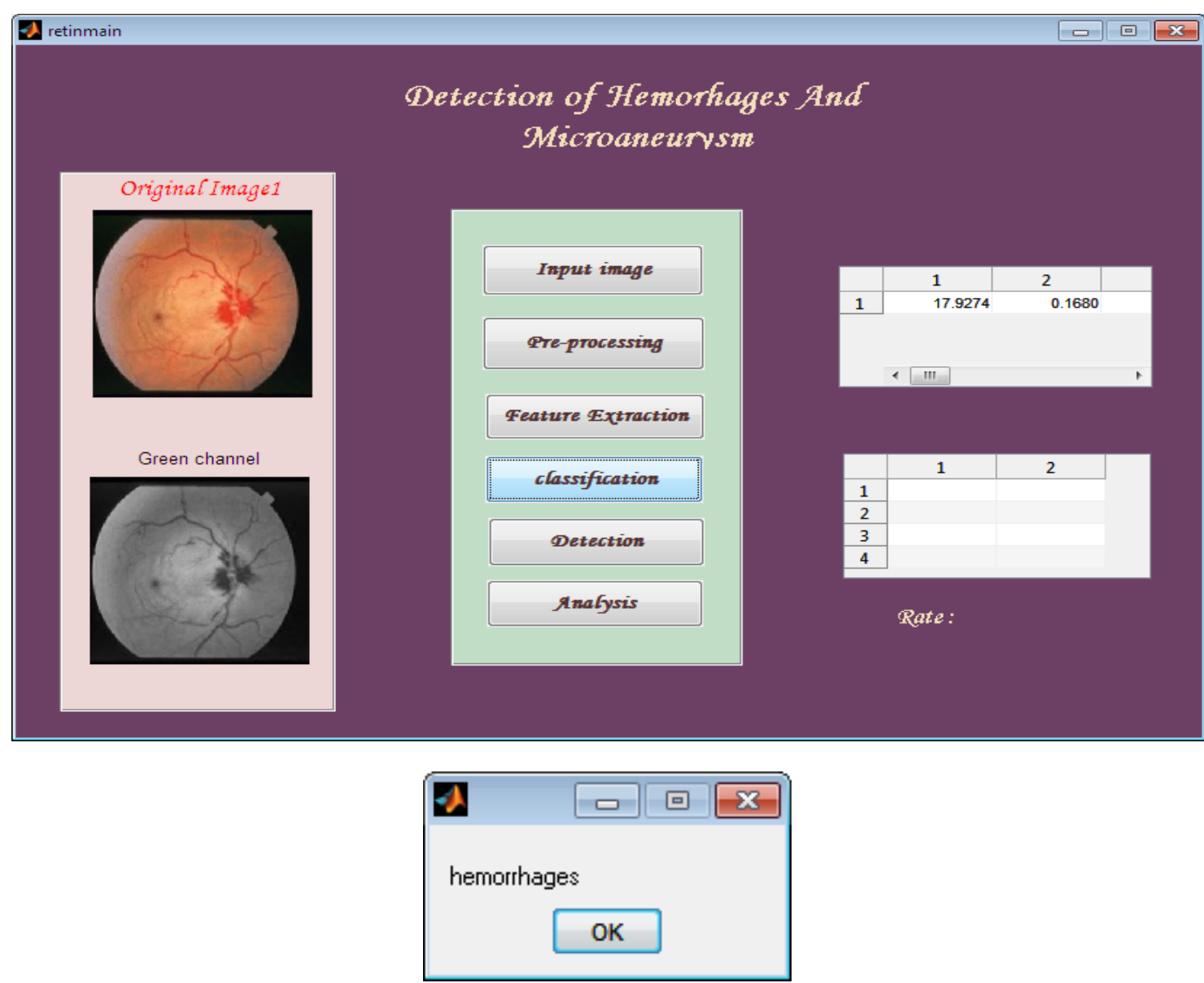

Fig.10.Detection of retinopathy disease.

(ished By:

Blue Eyes Intelligence Engineering \& Sciences Publication

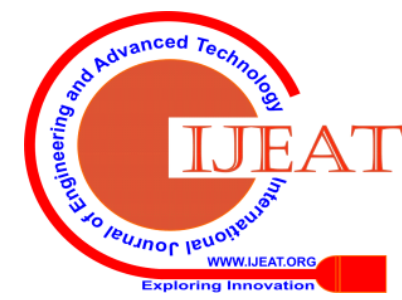


For distinguishing the ailment in retina order calculation is utilized to comapare the info picture with the dataset pictures. The calculation thinks about every one of the highlights of info picture utilizing cofusion framework.
In this figure the detected part of hemorrhages is shown using K-means theory

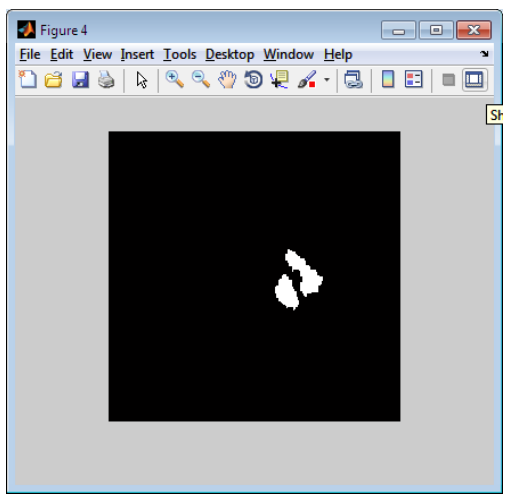

Fig.11. Detected part of hemorrhages

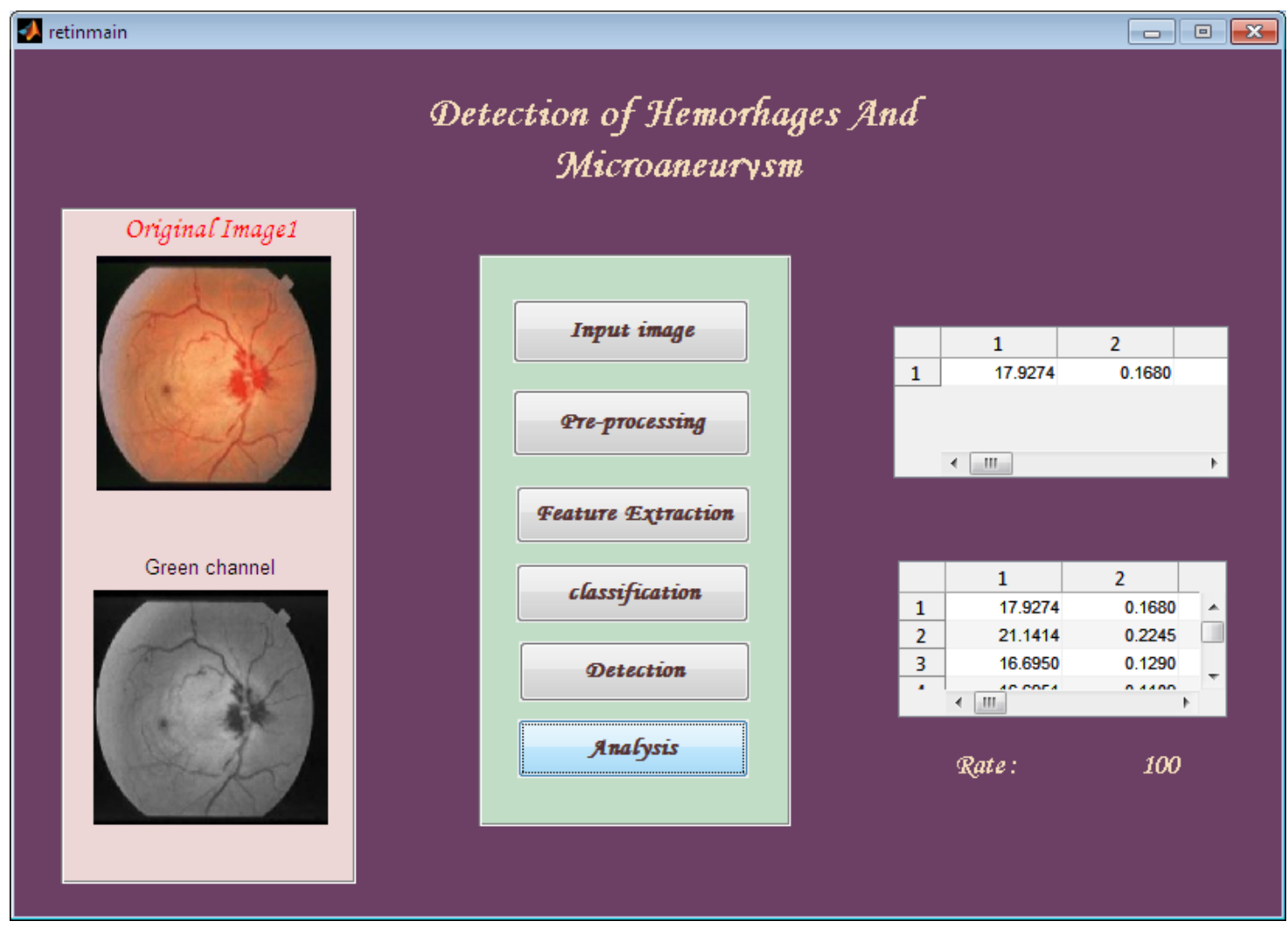

Fig.12. Analysis of result

This figure demonstrates the level of information coordinate in info picture and dataset. Every one of the parameters are appeared in base right plot and pace of coordinating is additionally shown.

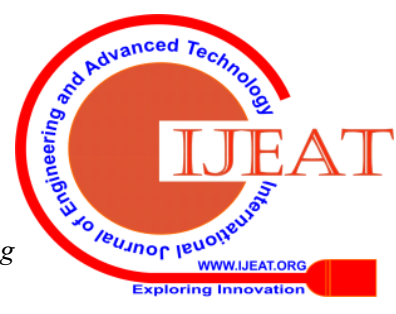




\section{Exploration of Retinopathy Disease using Machine Learning Methodology}

\section{Microanerysm:}

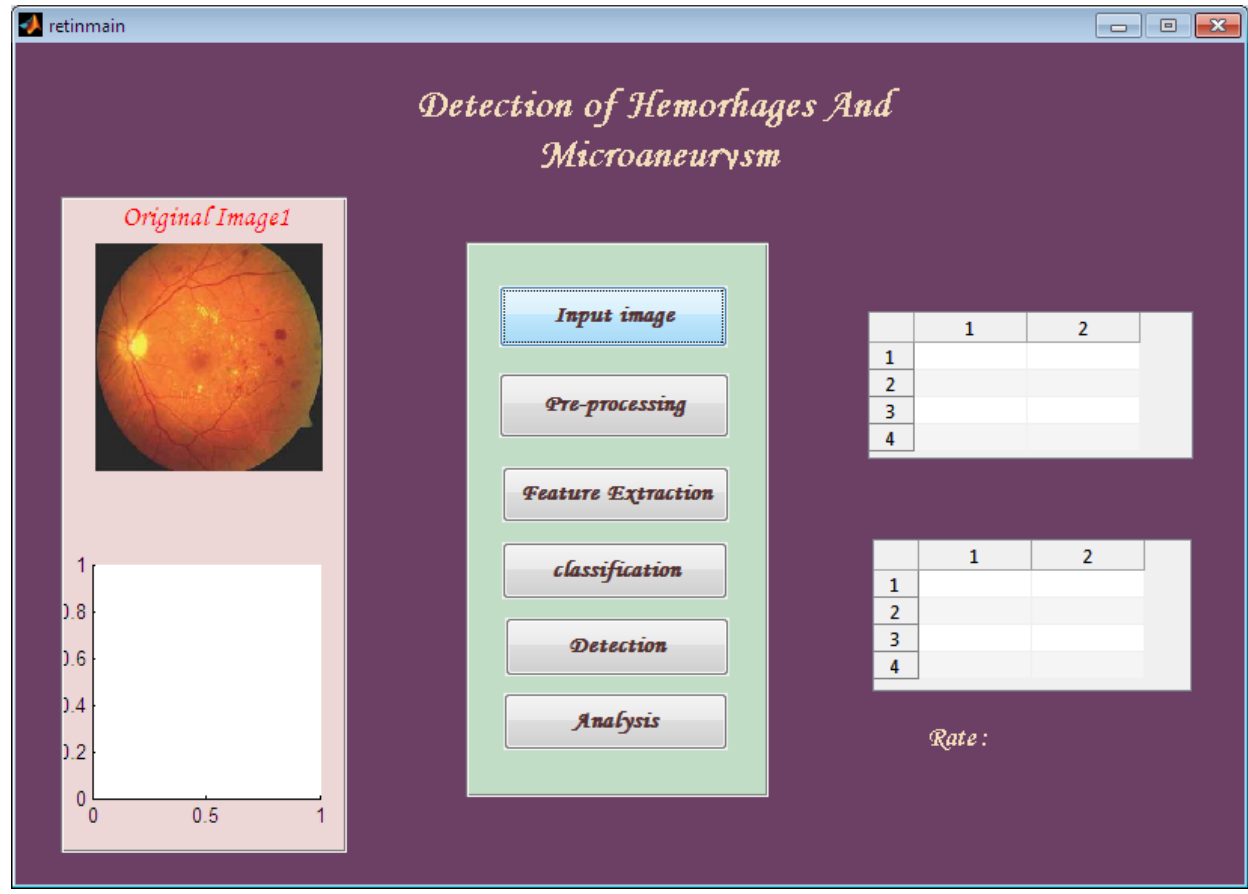

Fig.13. Front UI of the system.

In this form they have provided user with different GUI components for accessing the proposed system.In above form we have provided six buttons with four plots.

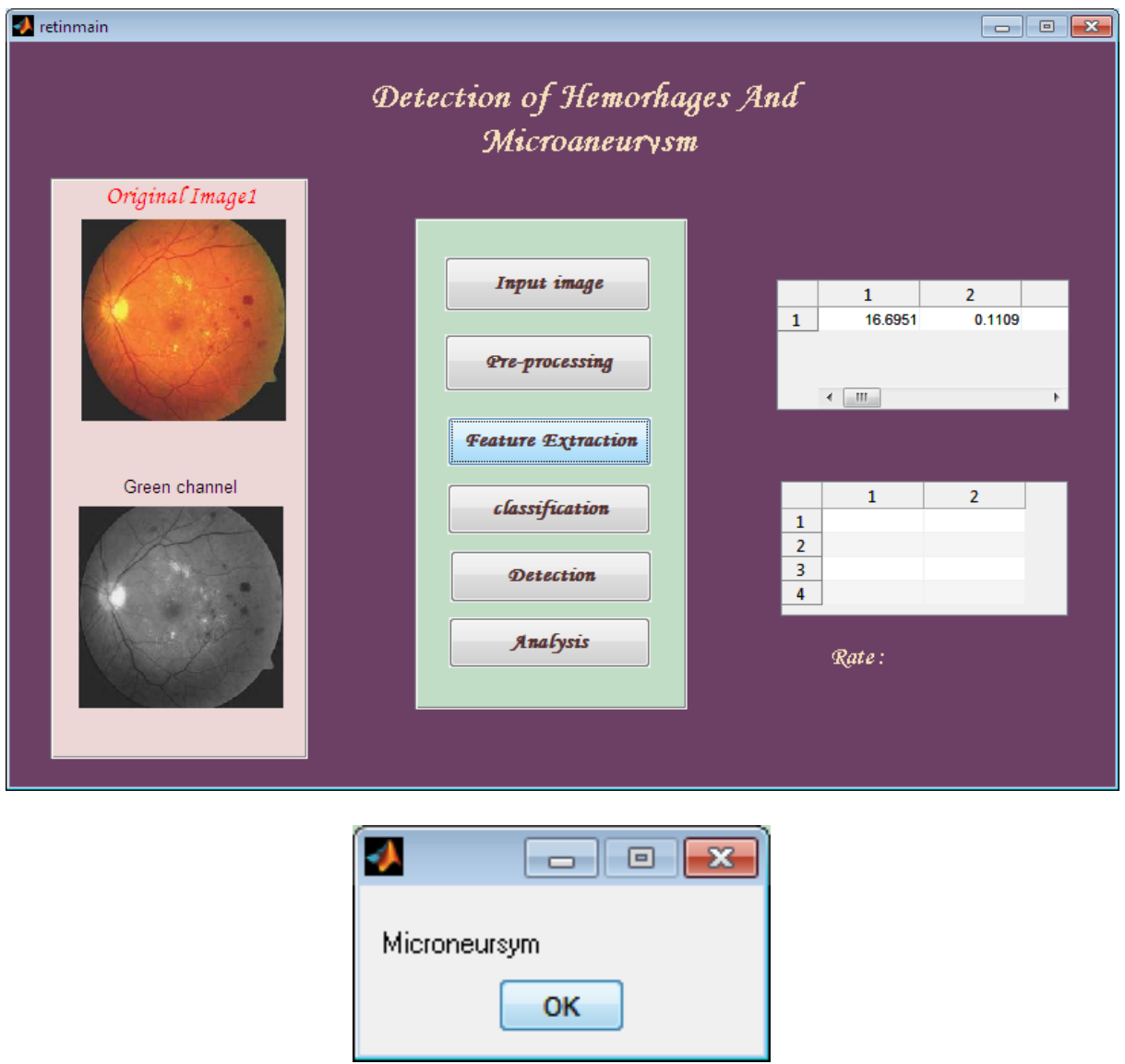

Fig.14. Detection of retinopathy disease.

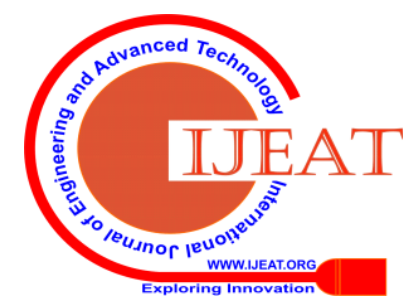


For detecting the disease in retina classification algorithm is used to comapare the input image with the dataset images. The algorithm compares all the features of input image using cofusion matrix.

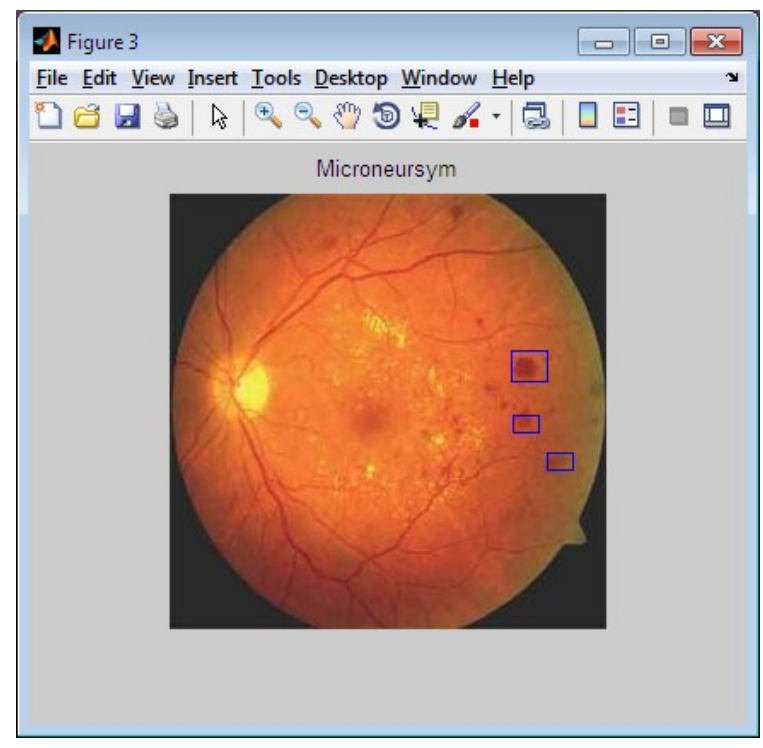

Fig.15.Detected part of Microneurysm

In this figure the detected part of hemorrhages is shown using K-means theory.

\section{RESULTS AND DISCUSSION}

The average sensitivity and specificity for the proposed ADDR is $92.44 \%$ and $84.5 \%$ respectively. Table below shows the comparison results with the other papers.

Table 1. Image Grade analysis system on the Dataset

\begin{tabular}{|l|l|l|l|}
\hline $\begin{array}{l}\text { DR } \\
\text { Grade }\end{array}$ & $\begin{array}{l}\text { Number } \\
\text { of } \\
\text { images }\end{array}$ & Sensitivity & Specificity \\
\hline G 0 & 27 & $87.65 \%$ & $100 \%$ \\
\hline G 1 & 23 & $100 \%$ & $86.88 \%$ \\
\hline G 2 & 16 & $100 \%$ & $100 \%$ \\
\hline G 3 & 33 & $100 \%$ & $100 \%$ \\
\hline
\end{tabular}

\section{CONCLUSION AND FUTURE SCOPE}

A blend of both precise and early finding just as right utilization of treatment can counteract visual impairment brought about by DR in over half all things considered. Diabetic retinopathy (DR) is a vascular malady of the retina which influences patients with diabetes mellitus. The whole world is impacted with the issue of Diabetic Retinopathy. At whatever point a patient has diabetes, it starts impacts human body unstable parts. So the condition ends up being extraordinarily unsafe for the person. Here in this assessment work it is endeavored to recognize Hemorrhages and scaled down scale aneurysms in various fundus pictures accumulated from various research establishments worldwide and available datasets. In starting it is required to confine RGB shades from the image. The green concealing is used for further taking care of. Further the diminish concealing picture is removed for getting the outside of the data picture. The part extraction counts are used to gathering. With the objective that it is possible to envision the current condition of the retinal picture. At the point when the situation is orchestrated the division estimations are used using flexible thresholding division. Its size is variable and regularly little so it tends to be effectively mistaken for clamor present in the picture. In human retina, there is a pigmentation variety, surface, size and area of human highlights from individual to individual. The more false positives happen when the veins are covering or contiguous with microaneurysms. So there is a need of a compelling robotized microaneurysm identification strategy so diabetic retinopathy can be treated at a beginning time and the visual deficiency because of diabetic retinopathy can be anticipated.

\section{FUTURE SCOPE}

A primary shortcoming of the calculation emerges from the way that the calculation relies upon vessel identification. This demonstrates the further need of improving the heartiness of this undertaking. Hemorrhages discovery could be additionally added to the framework so as to build its capacity to confirm the level of diabetic retinopathy.

\section{REFERENCES}

1. S. Wild, G. Roglic, A Green, "Global prevalence of diabetes: estimates for the year 2000 and projections for 2030," Diabetes Care, 27, pp.1047- 1053, 2014.

2. S. R. Nirmala, M. K. Nath, and S. Dandapat, "Retinal Image Analysis: A Review," International Journal of Computer \& Communication Technology (IJCCT), vol-2, pp. 11-15, 2011.

3. National Eye Institute, National Institutes of Health, "Diabetic Retinopathy: What you should know," Booklet, NIH Publication, no: 06-2171, 2013.

4. A. D. Fleming, K. A. Goatman, and J. A. Olson, "The role of haemorrhage and exudate detection in automated grading of diabetic retinopathy," British Journal of Ophthalmology, vol 94, no. 6, pp. 706- 711, 2010.

5. A. D. Fleming, S. Philip, K. A. Goatman, J. A. Olson, and P. F. Sharp, "Automated microaneurysm detection using local contrast normalization and local vessel detection," IEEE Trans. Med. Imag., vol. 25, no. 9, pp. 1223-1232, Sep. 2006.

6. M.Niemeijer,B. V. Ginneken, J. Staal, M. S. A. Suttorp-Schulten, and M. D. Abramoff, "Automatic detection of red lesions in digital color fundus photographs," IEEE Trans. Med. Imag., vol. 24, no. 5, pp. 584- 592, May 2005.

7. M. J. Cree, J. A. Olsoni, K. C. McHardyt, J. V. Forresters and P. F. Sharp, "Automated microaneurysms detection," IEEE conference, pp. 699-702, 1996.

8. A. Mizutani, C. Muramatsu, Y. Hatanaka, S. Suemori, T. Hara, and H. Fujita, "Automated microaneurysm detection method based on double ring filter in retinal fundus images," in Proc. SPIE, Med. Imag, Imag,Computer-Aided Diagnosis, vol. 7260, 2009.

9. K. Ram, G. D. Joshi and J. Sivaswamy, "A successive clutter rejectionbased-approach for early detection of diabetic retinopathy," IEEE Transaction on Biomediacl Engineering, vol. 58, no. 3, pp 664-673, Mar. 2011 


\section{Exploration of Retinopathy Disease using Machine Learning Methodology}

10. M. Esmaeili, H. Rabbani, A. M. Dehnavi, and A. Dehghani, "A new curvlet transform based method for extraction of red lesions in digital color retinal images," in Proc. ICIP, pp.4093-4096, 2010.

11. O. Fajarianto, M. I. Setiawan, A. Mursidi, D. Sundiman, and D. A. P. Sari, "The Development of Learning Materials for Introduction of Animals in Early Childhood Using Augmented Reality," 2018, pp. 722-727.

12. D. A. Puspito Sari, I. Listiyowati, T. Nefianto, and Lasmono, "The Discrepancy between The Programs and Disaster Management Policy in Klapanunggal District, Bogor, West Java," IOP Conf. Ser. Earth Environ. Sci., vol. 135, no. 1, p. 012011, Mar. 2018. 